\title{
US vows to combat antibiotic resistance
}

\section{Strategy lauded, but some fear it is lax on agricultural use.}

\section{BY SARA REARDON}

\section{A} push by the US government to stop the rise of antibiotic resistance has drawn broad praise from advocates who have long warned about this publichealth threat. Some, however, are concerned that the plan might not do enough to curb the use of these drugs in livestock.

Released by the White House on 18 September with an accompanying report by a presidential science advisory panel, the executive order instructs leaders of several US agencies to develop a fiveyear plan to limit the spread of resistance, using strategies such as developing new antibiotics

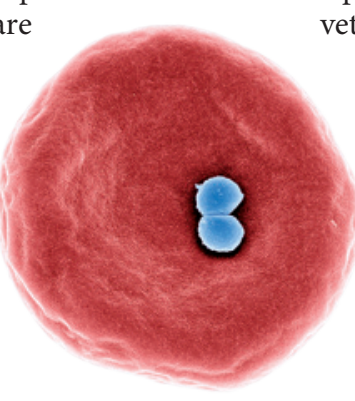

Staphylococcal bacteria (blue) on a red blood cell. contribute to the development of resistant bacteria. In December, the US Food and Drug Administration (FDA) issued voluntary guidance asking pharmaceutical firms to change labelling so that drugs cannot be marketed to fatten up farm animals, and requiring a veterinary surgeon to prescribe the drugs. According to the PCAST report, all 26 major manufacturers of antibiotics used in US farm animals have adopted these rules.

Two bills pending in the House of Representatives and the Senate would entirely ban farm-animal use of antibiotics that are also given to humans. But justifying morestringent limits is hampered by a poor understanding of the link and finding better ways to diagnose antibioticresistant infections quickly. It received the nod of approval from many experts.

"I find this report surprisingly detailed and surprisingly on target," says Stuart Levy, a physician and microbiologist at Tufts University in Boston, Massachusetts, who has long campaigned for prudent antibiotic use. It hits all the most important topics, he says: increased surveillance, better diagnostics, development of new drugs and more judicious use of existing antimicrobials - measures also outlined by the World Health Organization in April.

The use of antibiotics in animal husbandry is addressed in the White House strategy and in the report by the President's Council of Advisors on Science and Technology (PCAST). The report calls for collection of more data on the use of antibiotics on farms, and monitoring of whether policies to curb antibiotics affect the spread of resistance. But some advocates for careful antibiotic use feel that the plan will not do enough to stop the threat quickly. "They haven't proposed anything new," says Steven Roach of Carbondale, Illinois, who is an analyst for Keep Antibiotics Working, a coalition of advocacy groups that campaigns against antibiotic overuse. "The things they're saying people should do are endorsing the status quo."

Farmers sometimes give antibiotics to healthy livestock to prevent infection and boost growth, a controversial practice that is banned in some countries because it is thought to between agricultural antibiotic use and resistance in bacteria that infect humans.

"If I could wave my hand and ban it, I'd say let's do it," says Henry Chambers, an infectious-disease physician at the University of California, San Francisco. "But it's a very complicated area."

The PCAST report suggests that the FDA should continue to track whether the existing voluntary measures decrease agricultural antibiotic use, and investigate the extent to which giving the drugs to healthy animals contributes to resistance in human pathogens.

"It will be difficult to rigorously attribute changes in human antibiotic resistance patterns to changes in agricultural use - at least until much better surveillance systems are in place and until the flow of antibiotic resistance between reservoirs is much better understood," the PCAST report says.

PCAST's analysis, which is intended to guide the US agencies in their five-year plan, suggests spending US\$900 million per year on national monitoring systems - double the current level - and developing infrastructure to speed clinical trials of new antibiotics. The report also recommends spending $\$ 150$ million per year for 7 years on basic research into the spread of resistance and alternative strategies for growth promotion in livestock. To kick off the initiative, the White House announced a \$20-million prize for the first team to develop a rapid diagnostic tool for antibiotic-resistant infections. 